\title{
Use of ferrous fumarate to fortify foods for infants and young children
}

Richard Hurrell

Ferrous fumarate is currently recommended for use in the fortification of foods for infants and young children. This recommendation is based on the compound's good sensory properties and on results from isotope studies in adults that reported similar iron absorption values for ferrous fumarate and ferrous sulphate (relative bioavailability [RBV] of ferrous fumarate, 100). However, later isotope studies conducted on both iron-replete and iron-deficient young children found that iron absorption from ferrous fumarate was only about $30 \%$ of that achieved from ferrous sulphate (RBV, 30). The reasons for the differences observed in adults compared with children are unclear but could be related to the following factors: lower iron status in children resulting in greater iron absorption via upregulation from ferrous sulphate but not from ferrous fumarate; reduced gastric acid secretion in children leading to retarded dissolution of ferrous fumarate; or an influence of added ascorbic acid on $R B V$. Ferrous fumarate-fortified complementary foods have been demonstrated to improve iron status in iron-deficient infants and, more recently, to prevent iron deficiency equally as well as ferrous sulphate in iron-replete infants. However, current evidence indicates that iron-deficient infants and young children may absorb iron from ferrous fumarate less well than iron from ferrous sulfate and that, for equivalent efficacy, complementary foods targeted at such infants and young children should contain more iron in the form of fumarate.

(c) 2010 International Life Sciences Institute

\section{INTRODUCTION}

Complementary foods are the first solid foods fed to infants. They are introduced at about 6 months of age when human milk can no longer provide all the energy, protein, and micronutrients necessary to meet the infant's requirements for growth, and they usually form part of a mixed diet that includes breast milk. The provision of adequate iron in complementary foods is particularly important, since breast milk is extremely low in iron and iron stores in the liver of infants born at term last only for about 4-6 months. ${ }^{1}$ In low-birthweight infants, iron stores are smaller and provide a source of iron for an even shorter time.

Iron deficiency with or without anemia in infants and young children is still widespread and is of special concern in developing countries. ${ }^{2}$ Iron deficiency during infancy impairs normal brain development and can have a serious and detrimental effect on an infant's future. Iron-deficient anemic children are reported to have lower mental, social, emotional, and motor development scores than infants with normal iron status, ${ }^{3,4}$ which can result in lower school performance at 11-14 years of age. ${ }^{5}$ Studies from Chile found reduced nerve conduction velocity in response to an auditory signal in children who were previously iron-deficient and anemic; this was despite hemoglobin repletion with oral iron therapy ${ }^{6}$ and is strongly suggestive of decreased myelinization of nerve fibers.

Commercial, roller-dried, precooked, complementary foods and uncooked, blended foods provided through food aid programs, such as the US Food for Peace Program (7 USC 1721), are typically formulated based on

Affiliation: $R$ Hurrell is with the Institute of Food, Nutrition and Health, Swiss Federal Institute of Technology, Zurich, Switzerland.

Correspondence: R Hurrell, Swiss Federal Institute of Technology, Institute of Food, Nutrition and Health, Schmelzbergstrasse 7, LFV D20, 8092 Zurich, Switzerland. E-mail: richard.hurrell@ilw.agrl.ethz.ch, Phone: +41-44-632-8420, Fax: +41-44-632-1470.

Key words: bioavailability, ferrous fumarate, food aid, fortification, fortified blended foods, infant foods

doi:10.1111/j.1753-4887.2010.00312.x 
cereal alone, or on cereals with legumes or milk to provide adequate protein, and they are fortified with a range of micronutrients. The Food for Peace Program was originally authorized by Public Law 480 (PL480) in 1954. PL 480, Title II is the largest of the programs, and is designed by law "to respond to emergency food needs ... combat malnutrition, especially in children and mothers ... [and] promote food security" (7 USC Section 1721). Section 204 of the law (7 USC Section 1724) requires that $75 \%$ of commodities for nonemergency programs be made up of fortified, processed, and bagged products. While milk was included in the original formulation of the products for preschoolers in the 1960s, the cereal blends with milk powder are no longer obtained for distribution, principally because of the higher cost of milk as a protein source (in comparison to soy). The commercial products often contain additional components, such as fruit. These roller-dried or blended products are technically difficult to fortify with iron, since water-soluble iron compounds of high relative bioavailability, such as ferrous sulphate, may result in off-putting flavors, due to fat oxidation reactions during storage, and may cause adverse color reactions, particularly in the presence of fruit or vegetables. ${ }^{7}$ It has therefore been the custom to fortify dry cereal products with iron compounds that are insoluble in water in order to avoid the undesirable sensory changes.

Electrolytic iron is commonly used to fortify commercial infant cereals in the United States, whereas European manufacturers usually add ferrous fumarate or ferric pyrophosphate. ${ }^{8}$ The US Food for Peace Program fortifies the cereal/legume blended products (such as corn soy blend) with ferrous fumarate and the fortified flour product (such as wheat flour) with reduced (325 mesh) iron, without specifying the type. Ferrous sulphate, ferrous fumarate, and electrolytic iron powder (at twice the level of iron as sulphate or fumarate) are recommended for the fortification of cereal-based complementary foods in the World Health Organization Guidelines on Food Fortification ${ }^{9}$ and by the Pan American Health Organization. ${ }^{10}$ None of the different forms of reduced iron are recommended at the present time. In order to ensure adequate iron absorption in the presence of high phytic acid from cereals and legumes, it is also recommended that ascorbic acid be added with the iron compound at a 2:1 molar ratio compared to iron. ${ }^{79}$ This recommendation mainly applies to precooked commercial infant cereals, which are packed in airtight, moistureresistant packages and are made into a pap with hot potable water or milk. When fortified foods (including blended foods) are poorly stored or cooked before consumption, ascorbic acid is extensively degraded.

The recommendation to add ferrous fumarate or electrolytic iron to complementary foods for infants and young children is based on relative bioavailability (RBV) studies performed in adults. In these studies, absorption of the test iron compound is compared to that of ferrous sulphate, a compound that readily enters the common iron pool in the gastric juice. While there have been no direct comparisons of iron absorption from iron-fortified foods in adults as compared to infants or young children, there are indications that adults and infants respond similarly to enhancers and inhibitors of absorption. ${ }^{11}$ In addition, the limited available evidence suggests that infants between 6 and 9 months of age also regulate their iron absorption in relation to iron intake and to the size of their body iron stores. ${ }^{12}$

When determining recommendations for the choice of iron fortificant, it has been assumed that if an iron compound has a high RBV in adults, then it will also have a high RBV in children. Ferrous fumarate is as well absorbed as ferrous sulphate in adults ${ }^{13}$ and electrolytic iron appears to be absorbed about half as well as ferrous sulphate. ${ }^{8}$ Until recently, no relative bioavailability studies had been performed in infants and young children consuming iron-fortified complementary foods. However, two recent studies of young children have cast doubt on the suitability of ferrous fumarate for complementary food fortification, ${ }^{14,15}$ at least in relation to the iron and ascorbic acid levels tested in these studies. In young children, the RBV of ferrous fumarate was only $30-35 \%$ of ferrous sulphate. The present review, conducted as part of SUSTAIN's Food Aid Quality Enhancement Project, evaluates the usefulness of ferrous fumarate to fortify foods for infants and young children and discusses the use of alternative iron compounds.

\section{Ferrous fumarate absorption studies in adults}

In an attempt to find a highly bioavailable iron compound to add to commercial infant cereals, a series of sensory studies was conducted in adults using cereals containing $10 \mathrm{mg}$ and $50 \mathrm{mg} \mathrm{Fe} / 100 \mathrm{~g}$, followed by rat hemoglobin repletion tests and human bioavailability studies. ${ }^{13}$ Based on these experiments, ferrous fumarate and ferrous succinate were recommended as alternatives to ferrous sulphate for fortifying infant cereals with iron. Unlike ferrous sulphate, ferrous fumarate and ferrous succinate caused few or no sensory changes in the stored cereal products or color changes in the porridges made by adding hot milk or water. In addition, when the experimental iron compounds were synthesized using ${ }^{55} \mathrm{Fe}$, the RBV values in human subjects were equivalent to the RBV value of ferrous sulphate labeled with ${ }^{59} \mathrm{Fe}$. In the human studies, the intrinsically labeled compounds were added to a commercial wheat-milk infant cereal and fed to iron-replete adults. These various findings have been 
Table 1 Iron absorption studies in adult men and women from food fortified with ferrous fumarate or ferrous sulphate.

\begin{tabular}{|c|c|c|c|c|c|c|}
\hline \multirow[t]{2}{*}{ Reference $^{\dagger}$} & \multirow[t]{2}{*}{ Test meal } & \multirow[t]{2}{*}{ Fe (mg/serving) } & \multirow{2}{*}{$\begin{array}{l}\text { Ascorbic acid } \\
\text { (mg/serving) }\end{array}$} & \multicolumn{2}{|c|}{ Mean Fe abs. (\%) } & \multirow[t]{2}{*}{$\mathrm{RBV}^{\ddagger}$} \\
\hline & & & & Fumarate & Sulfate & \\
\hline Hurrell et al. $(1989)^{13}$ & Wheat-milk infant cereal & 7.5 & 35 & 2.58 & 2.58 & 100 \\
\hline \multirow{3}{*}{ Hurrell et al. $(1991)^{16}$} & Chocolate drink powder & & & & & \\
\hline & Fe added after drying & 5 & 25 & 3.31 & 2.82 & 117 \\
\hline & Fe added before drying & 5 & 25 & 5.27 & 2.62 & 201 \\
\hline \multirow{3}{*}{ Hurrell et al. $(2000)^{17}$} & Wheat infant cereal & 5 & - & 2.06 & 2.20 & 94 \\
\hline & Wheat-soy infant cereal & 5 & - & 0.93 & 0.73 & 128 \\
\hline & Quinoa infant cereal & 5 & - & 0.57 & 0.63 & 91 \\
\hline Fidler et al. $(2003)^{18}$ & Wheat-milk infant cereal & 5 & - & 3.0 & 3.1 & 97 \\
\hline
\end{tabular}

${ }^{\dagger}$ References include all radio isotope studies, except ref. 18 which used stable isotopes, testing absorption of fumarate and sulfate in same subject. Subjects were mostly iron replete (serum ferritin $>12 \mu \mathrm{g} / \mathrm{L}$ ).

${ }^{\ddagger}$ RBV, relative bioavailability; "absorption fumarate/absorption sulfate" $\times 100$.

ascribed to the fact that ferrous fumarate and ferrous succinate are slowly soluble in water but readily soluble in dilute acids, such as the gastric juice. As a result, they are nonreactive enough to avoid organoleptic problems, yet adequately soluble in the gastrointestinal lumen to be available for absorption. In the human studies, iron absorption from a cereal fortified with $7.5 \mathrm{mg}$ iron as ferrous sulphate and $35 \mathrm{mg}$ ascorbic acid per $100 \mathrm{~g}$ dry cereal was around $3 \%$ (Table 1 ). The RBV values were 100 for ferrous fumarate (Table 1) and 92 for ferrous succinate, as compared to 39 for ferric pyrophosphate and 75 for ferric saccharate, which were also tested. Ascorbic acid was added along with all iron compounds. Ferrous fumarate, ferrous succinate, ferric pyrophosphate, and ferric saccharate did not cause sensory problems. In addition, encapsulated ferrous sulphate did not provoke fat oxidation during storage, but it did cause color changes with some cereals when hot water or hot milk was added to make the pap.

Several other studies have confirmed the high RBV value of ferrous fumarate in adults (Table 1). Intrinsically radio-labeled ferrous fumarate added to a chocolate drink powder immediately prior to consumption was absorbed to the same degree as ferrous sulphate (RBV 117) by iron-replete adults, and when added to the product during manufacturing (prior to vacuum drying), the RBV value rose to $201 .{ }^{16}$ Ferrous fumarate absorption increased, while ferrous sulphate absorption remained unchanged. The reasons for this are unknown.

The absorption of intrinsically radio-labeled ferrous fumarate was later compared to ferrous sulphate and NaFeEDTA added to a wheat cereal, a wheat/soy cereal, and a quinoa cereal. Relative to ferrous sulphate, the RBV values of ferrous fumarate in iron-replete adults were 94 , 128 , and 91 , respectively, for the three different cereal products, as compared to RBV values of 258,459 , and 314 for NaFeEDTA added to the same products. ${ }^{17}$ No ascorbic acid was added in these studies, and mean iron absorp- tion from ferrous fumarate in the iron-replete adults varied between 0.6 and $2 \%$ depending on the phytate content of the cereal porridges (Table 1).

More recently, Fidler et al. ${ }^{18}$ compared the absorption of ferrous fumarate intrinsically labeled with the stable iron isotope ${ }^{57} \mathrm{Fe}$, with ferrous sulphate labeled with ${ }^{58} \mathrm{Fe}$. The isotopically labeled iron compounds were added to a wheat/milk infant cereal ( $5 \mathrm{mg} \mathrm{Fe} / 50 \mathrm{~g}$ meal) and fed to adult women, of whom about one-third had low iron stores (serum ferritin $<12 \mu \mathrm{g} / \mathrm{L}$ ). Iron absorption from ferrous sulphate was $3.1 \%$, compared to $3 \%$ for ferrous fumarate (RBV 97) (Table 1). Adding ascorbic acid at a 4:1 molar ratio relative to iron increased the absorption of ferrous fumarate about twofold. In adolescent Guatemalan girls (12-13 years), all of whom had normal hemoglobin values and $<10 \%$ of whom were iron deficient, mean iron absorption from corn tortillas consumed with bean paste and fortified with ${ }^{57} \mathrm{Fe}$-labeled ferrous fumarate was $5.5 \%$ and $6.2 \%$ in two separate studies, as compared to $5.5 \%$ iron absorption in a third group of girls who were fed the same meal fortified with ${ }^{58} \mathrm{Fe}$-labeled ferrous sulphate. ${ }^{19}$

Based on these relative bioavailability studies carried out in mostly iron-replete adults and adolescents with iron compounds intrinsically labeled with either radio or stable iron isotopes, ferrous fumarate was judged to be as well absorbed as ferrous sulphate and was recommended for use in the iron fortification of complementary foods for infants and young children.

\section{Ferrous fumarate absorption studies in infants and young children}

The existing literature contains five published reports of studies measuring iron absorption from ferrous fumarate in infants or young children (Table 2), but only two of these studies compared the absorption of ferrous fumarate directly with ferrous sulphate absorption in the same 


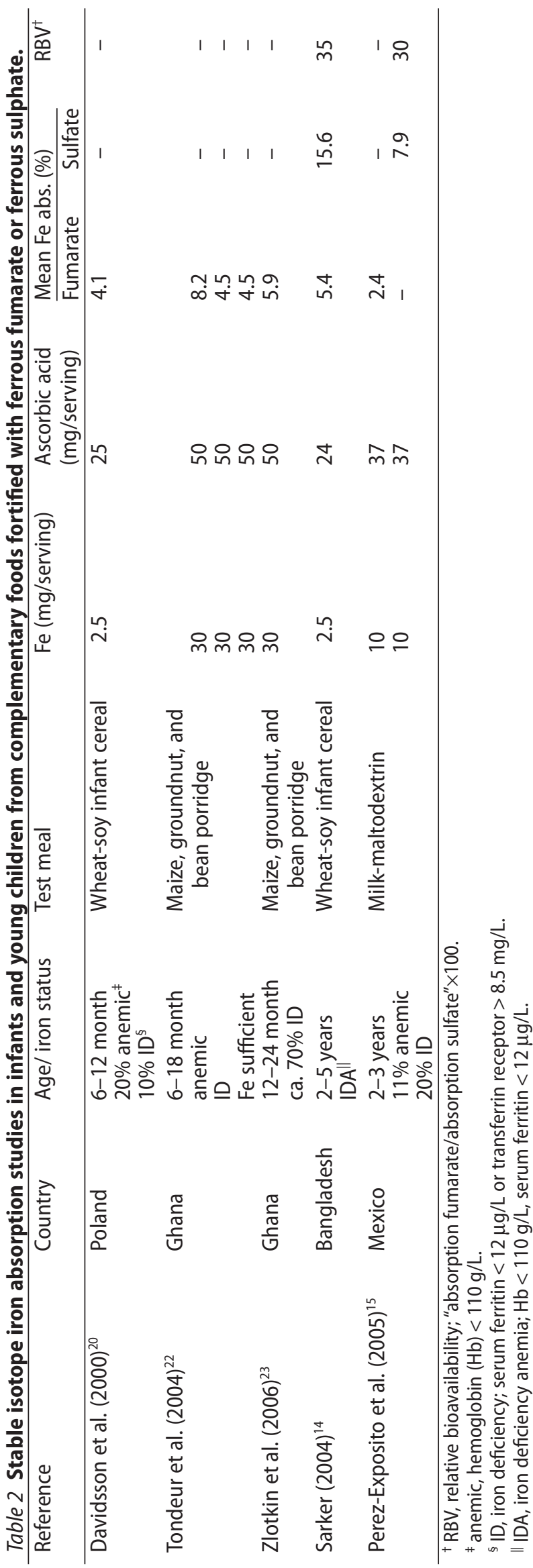

child. All five of the studies used ferrous fumarate intrinsically labeled with ${ }^{57} \mathrm{Fe}$.

In the first study, mean iron absorption by ten Polish infants aged 6-12 months who were fed a wheat/ soy infant cereal fortified with ferrous fumarate $(10 \mathrm{mg}$ $\mathrm{Fe} / 100 \mathrm{~g})$ and ascorbic acid (100 mg/ $100 \mathrm{~g}$ ) was $4.1 \%$ compared to $1.3 \%$ by the same infants fed an identical cereal fortified with ferric pyrophosphate. ${ }^{20}$ Two infants were anemic (hemoglobin $<110 \mathrm{~g} / \mathrm{L}$ ) and one further infant had a serum ferritin level below $12 \mu \mathrm{g} / \mathrm{L}$. Each infant consumed $25 \mathrm{~g}$ cereal made into porridge with hot water. A comparison with ferrous sulphate absorption was not made. Two further studies of young children have been conducted with intrinsically labeled ferrous fumarate encapsulated in a hydrogenated soybean oil matrix, which represented $40 \%$ of the fortificant by weight. According to Zimmermann, ${ }^{21}$ this amount and type of capsule should not influence iron bioavailability.

In a study performed in 6-18-month-old children, ${ }^{22}$ $30 \mathrm{mg}$ and $45 \mathrm{mg}$ of iron as encapsulated ferrous fumarate was added together with other micronutrients ("Sprinkles") to maize, groundnut, and bean porridge at the time of feeding. The micronutrient mix provided $50 \mathrm{mg}$ ascorbic acid. Fractional iron absorption did not differ between doses and was $8.2 \%$ in children who were iron deficient and anemic, $4.5 \%$ in children with iron deficiency, and $4.6 \%$ in children with sufficient levels of iron. In a follow-up study ${ }^{23}$ conducted using the same protocol, iron absorption from $30 \mathrm{mg} F$ as intrinsically labeled encapsulated ferrous fumarate in 12-24-monthold children (most of whom were iron deficient) was reported to be around $6 \%$. No comparison with ferrous sulphate was made.

Two further studies, one in Bangladesh ${ }^{14}$ and one in Mexico, ${ }^{15}$ compared iron absorption in young children fed complementary foods fortified with ferrous fumarate or ferrous sulphate. In Bangladesh, a wheat/soy infant cereal $(25 \mathrm{~g})$ fortified with ${ }^{57} \mathrm{Fe}$-labeled ferrous fumarate or ${ }^{58} \mathrm{Fe}$-labeled ferrous sulphate $(10 \mathrm{mg} \mathrm{Fe} / 100 \mathrm{~g})$ plus ascorbic acid $(94 \mathrm{mg} / 100 \mathrm{~g})$ was fed to two groups ( $n=12$ in each group) of 2 -5-year-old children. ${ }^{14}$ All of the children were iron deficient and anemic (hemoglobin $<110 \mathrm{~g} / \mathrm{L}$; serum ferritin $<12 \mu \mathrm{g} / \mathrm{L}$ ); one group of children had been diagnosed with Helicobacter pylori infection and the second group was free of $H$. pylori. In the group of children without $H$. pylori, mean iron absorption from ferrous fumarate was 5.4\% compared to $16.6 \%$ from ferrous sulphate (RBV 35) (Table 2). In the children with $H$. pylori infection, mean iron absorption from ferrous fumarate was $5.3 \%$, as compared to $19.7 \%$ from ferrous sulphate (RBV 27). Treatment of the $H$. pylori infection for 14 days with amoxicillin, clarithromycin, and omeprazole cured the 
infection in most children but had little influence on iron absorption. Mean iron absorption from ferrous fumarate was $6.4 \%$ compared to $22.5 \%$ from ferrous sulphate (RBV 28). Gastric acid output was slightly but significantly lower in the children infected with $H$. pylori but it returned to normal after treatment.

In the study performed in Mexico, ${ }^{15}$ two separate groups of 17 (group 1) and 19 (group 2) 2-3-year-old children were fed a milk/maltodexrin complementary food fortified with ${ }^{57}$ ferrous sulphate (group 1) or ${ }^{57}$ ferrous fumarate (group 2). Approximately $44 \mathrm{~g}$ of the complementary food mixture, containing $10 \mathrm{mg}$ iron (1.2:1, ascorbic acid: iron), was mixed with about $25 \mathrm{~mL}$ water and fed to the children; $11 \%$ of them were anemic and $20 \%$ were iron deficient based on low ferritin levels. The iron status of the two test groups of children was found to be similar; as judged by a similar level of iron absorption from a reference iron dose. Mean iron absorption in the children who were fed the complementary food fortified with ferrous sulphate was $7.9 \%$, as compared to $2.4 \%$ from the group of children who were fed the same complementary food fortified with ferrous fumarate (RBV 30).

The only efficacy study to be published thus far was carried out in 6-12-month-old South African infants who received maize meal fortified with ferrous fumarate at $27.5 \mathrm{mg} \mathrm{Fe} / 100 \mathrm{~g}$ and vitamin $\mathrm{C}$ at a 1.6 molar ratio compared to iron. ${ }^{24}$ At baseline, $58 \%$ of the infants were iron deficient and $46 \%$ were anemic. The maize meal was also fortified with zinc and $\beta$-carotene. Infants were fed $50 \mathrm{~g}$ maize meal per day as one or two meals. This provided a total of about $14 \mathrm{mg}$ iron per day for 6 months and increased the hemoglobin significantly by $9 \mathrm{~g} / \mathrm{L}$ and the serum ferritin by $9.4 \mu \mathrm{L}$ in comparison with controls who received the non-fortified maize porridge. The proportion of infants with anemia decreased from $45 \%$ to $17 \%$ in the fortified porridge group, whereas the prevalence of anemia remained at $>40 \%$ in the control group. This is the only classic efficacy study performed to date that has demonstrated that ferrous fumarate fortified foods improve iron status.

Another recent study conducted in Bangladesh supports the usefulness of ferrous fumarate (and ferric pyrophosphate) in the iron fortification of complementary foods $\mathrm{s}^{25}$; the study showed that the compounds can help maintain adequate iron status in iron-replete children, in a similar manner as ferrous sulphate. The study was conducted as a double-blind efficacy study in 235 nonanemic children aged 6-24 months; the children were randomized into three groups that received one serving per day of iron-fortified infant cereal containing $9.3 \mathrm{mg}$ iron in the form of sulphate, fumarate, or pyrophosphate plus ascorbic acid at a 3:1 molar ratio. The level of iron was about fourfold greater than the level usually added to a commercial infant cereal, and the ascorbic acid level was $50 \%$ higher. The children were fed the fortified wheat/ milk cereal 6 days a week for 9 months. No significant difference was observed among the three groups in the proportion of children developing anemia during the study (range, 18-22\%). Children who became anemic were immediately removed from the study and treated with iron. At 9 months, all of the children remaining in the study had normal serum transferrin receptor concentrations. Two children in the sulphate group, one child in the pyrophosphate group, and zero children in the fumarate group had serum ferritin values below $12 \mu \mathrm{L}$. In this study, the ferrous fumarate-fortified cereal was equally as good as the ferrous sulphate-fortified cereal at maintaining adequate iron status and preventing iron deficiency in the children. This study provides evidence that, with a daily dose of $9 \mathrm{mg}$ fortification iron plus ascorbic acid at a 3:1 molar ratio, ferrous fumarate is as good as ferrous sulphate for preventing iron deficiency in initially ironreplete children. The high iron level provided by fumarate and the higher than normal ascorbic acid level could have contributed to this finding.

\section{Variation in relative bioavailability with subjects' iron status}

For many years, the RBV value of an iron compound has been used to evaluate its suitability for food fortification. Initially, the RBV value was obtained using rat hemoglobin repletion studies and, more recently, using isotopic studies in humans consuming fortified foods. Iron compounds are ranked in comparison to the reference compound ferrous sulphate. It was implicitly assumed that under all situations the test iron compound would have the same relative absorption when compared to ferrous sulphate. Recently, however, it was suggested that iron absorption from ferrous sulphate is upregulated more readily in irondeficient humans than iron absorption from waterinsoluble iron compounds and that iron absorption from ferrous sulphate is also more sensitive to inhibitors and enhancers of iron absorption. ${ }^{26}$ Further unpublished data confirms that iron absorption in iron-deficient women occurs via upregulation from foods fortified with ferric pyrophosphate less than from foods fortified with ferrous sulphate (Zimmermann M, personal communication). Further evidence exists from a recent stable isotope study conducted in Mexico with non-anemic and largely ironreplete women, infants, and young children that the RBV value of ferrous fumarate is around 100 in all population groups (Harrington $\mathrm{M}$, personal communication). The subjects in that study included young women, their 6-24month-old infants, and young children between the ages of 2 and 5 years, with 20 subjects per group; all of the subjects were fed a sweetened drink that was based on 
degermed (low phytate) maize flour and milk powder and fortified with ferrous fumarate or ferrous sulphate. Seven women, one child, and one infant had serum ferritin values below $12 \mu \mathrm{L}$. Within each population group, no significant differences in iron absorption were found between ferrous sulphate and ferrous fumarate, although mean iron absorption depended on iron status and was $19 \%$ in women, $7 \%$ in infants, and $6 \%$ in young children. RBV values for ferrous fumarate were 86 in women, 97 in infants, and 106 in children.

Thus, the presently available evidence indicates that the iron status of women influences the RBV of iron compounds such as ferric pyrophosphate, which are poorly soluble in dilute acid. However, the influence of the iron status of infants and children on the RBV of ferric pyrophosphate and ferrous fumarate is not known and the low iron status of the infants in the Bangladesh study ${ }^{14}$ could be an explanation for the low RBV reported for ferrous fumarate. ${ }^{14,15}$ The children in the Mexico study, ${ }^{15}$ however, were a mixture of iron-deficient $(20 \%$ low serum ferritin, $11 \%$ anemic) and iron-replete subjects. An additional explanation could be that in some situations children have a lower gastric acid output than adults and that fumarate does not completely dissolve in the gastric juice during the digestion process. ${ }^{14}$ If this is the case, then all poorly soluble iron fortification compounds, including the different forms of elemental iron and ferric pyrophosphate, would be likewise less well absorbed relative to ferrous sulphate in young children compared with adults. The differential effects of ascorbic acid and phytic acid on iron absorption from ferrous sulphate and other iron compounds could also influence the RBV value.

When designing an iron-fortified food, the food manufacturer is advised to choose the iron compound with the highest RBV that causes no sensory problems. The level of fortification should be based on the needs of the consumer, the estimated or measured iron absorption, and the level of consumption of the food vehicle by the target population. Absorption can be increased with ascorbic acid. An RBV of less than 100 does not mean that the iron compound is unsuitable for fortification and similarly an RBV of 100 does not ensure success. Based on the fractional iron absorption from the fortified food, the iron concentration in the food can be increased so as to meet the consumer's iron needs for absorbable iron. The World Health Organization $^{9}$ recommends that the RBV should be at least 50 and, in such a situation, the iron compound (ferric pyrophosphate, electrolytic iron) should be added at twice the level of ferrous sulphate. An iron compound is an acceptable iron fortificant if the amount of additional absorbable iron provided by the fortified food meets the needs of the target population. ${ }^{9}$

\section{Achieving adequate iron absorption from iron-fortified foods fed to infants and young children}

Optimizing the level of ferrous fumarate. Although two studies have reported that iron absorption by infants from ferrous fumarate-fortified complementary foods is only $30 \%$ of that from ferrous sulphate, mean iron absorption from ferrous fumarate-fortified cereal foods in all studies has varied from $2.4 \%$ to $8.2 \%$ (Table 2) depending on the iron status of the children, the level of iron fortification, and the type and amount of the meal. Iron absorption was $2.4 \%$ from a $44 \mathrm{~g}$ meal containing $10 \mathrm{mg}$ iron, ${ }^{15} 5.4 \%$ from a $25 \mathrm{~g}$ meal containing $2.5 \mathrm{mg}$ $\mathrm{Fe},{ }^{14} 4.5-8.2 \%$ in a maize, groundnut, and bean porridge containing $30 \mathrm{mg}$ of iron as encapsulated ferrous fumarate $^{22,23}$ and 6-7\% in infants and young children consuming $60 \mathrm{~g}$ of a maize milk drink with $2.5 \mathrm{mg}$ of iron in a recent, as yet unpublished, Mexican study.

From this information, a suitable ferrous fumaratefortified complementary food can be developed by adjusting the level of ferrous fumarate fortification so that the required amount of iron is absorbed. According to the World Health Organization/Food and Agriculture Organization, ${ }^{27}$ a 7 -12-month-old infant requires $18.6 \mathrm{mg}$ iron intake from a $5 \%$ bioavailability diet $(0.93 \mathrm{mg}$ absorbable $\mathrm{Fe} /$ day) and a 1-3-year-old child requires $11.6 \mathrm{mg}$ iron intake (0.63 mg absorbable Fe/day). Assuming that little or no iron is provided by other dietary components, the amount of added iron in the average intake of complementary food should meet the requirements of the infant or young child. According to Dewey and Brown, ${ }^{28} 25,50$, and $140 \mathrm{~g}$ of cereal-based complementary food are required to meet the daily energy needs of the 6-8-, 9-11-, and 12-23-month-old children, respectively. Thus, in order to provide 9-11-month-old children with $0.9 \mathrm{mg}$ absorbable iron per day in $50 \mathrm{~g}$ of a cereal-based meal, the meal should be fortified with $19 \mathrm{mg}$ iron as ferrous fumarate ( $36 \mathrm{mg} \mathrm{Fe} / 100 \mathrm{~g}$ ), assuming $5 \%$ iron absorption, which is the average reported in the published studies. A higher level of fortification would be necessary for the younger children who consume less or to allow for a lower fractional absorption. For the 1-3year-old child whose requirements are less and who may have other sources of iron in the diet, a single $50 \mathrm{~g}$ meal containing $10 \mathrm{mg}$ of iron as ferrous fumarate should suffice if absorption is $5 \%(20 \mathrm{mg} \mathrm{Fe} / 100 \mathrm{~g})$. These calculations assume that ascorbic acid is present in the meal in at least a 1:1 molar ratio with iron. While this should be achievable in precooked, well-packaged cereal foods that are made into a pap with hot water or milk, it may not be possible to add ascorbic acid to cereal foods that need to be cooked before consumption.

In the recent study conducted in iron-replete 7-24month-old Bangladeshi children, one cereal meal per day 
with $9 \mathrm{mg} \mathrm{Fe}$ as ferrous fumarate maintained iron status in $80 \%$ of the children over a 9 -month period, while $20 \%$ of the cohort developed anemia. ${ }^{25}$ It is likely that an increase in the fortification level would have resulted in fewer children developing anemia. Even higher fortification levels would be needed if most of the children were iron deficient at the start of weaning rather than being iron replete as in this study. In poor communities in Bangladesh, $90 \%$ of the breastfed children were found to be anemic at the start of weaning, presumably because of the low iron content of human milk and limited maternal transfer of iron stores during gestation.

Alternative iron compounds. If ferrous sulphate causes no unacceptable sensory changes during storage or preparation of the pap, then this would be the best iron compound with which to fortify foods for infants and young children. Assuming 10\% iron absorption and a complementary food intake of $50 \mathrm{~g} /$ day, a fortification level of $18 \mathrm{mg} \mathrm{Fe} / 100 \mathrm{~g}$ as ferrous sulphate would cover the needs of 9-11-month-old children for absorbable iron. (For sulphate, $10 \%$ iron absorption is estimated, as opposed to $5 \%$ for fumarate, since iron absorption from sulphate has been shown to be three times higher than that from fumarate in iron-deficient children and similar to fumarate in iron-replete children.) Encapsulated ferrous sulphate (maximum 50\% capsule) would also be suitable, if added at the same concentration. Encapsulation in hydrogenated fat would prevent any fat oxidation during storage of cereal foods but would not necessarily prevent unwanted color reactions on preparation of the pap if fruits or vegetables are included. ${ }^{13}$ Other soluble iron compounds, such as ferrous gluconate, would be expected to have the same high relative bioavailability as ferrous sulphate, and to cause similar sensory problems. However, no systematic evaluation of alternative soluble compounds has been made.

Two other potential iron compounds for complementary food fortification are ferrous succinate and NaFeEDTA; however, both require further study. While ferrous succinate was proposed previously, ${ }^{13}$ together with ferrous fumarate, for infant cereal fortification, it has never been used commercially as an iron fortificant. Before ferrous succinate could be recommended, further absorption studies would be needed in infants and young children fed cereal foods fortified with intrinsically labeled ferrous succinate and ferrous sulphate. NaFeEDTA absorption would be expected to be 2-3 times that of ferrous sulphate in the absence of ascorbic acid. ${ }^{29}$ While this compound does not provoke fat oxidation in stored cereals, adverse color reactions are possible. No systematic studies have been made in infants and young children and a recent SUSTAIN Task Force recommended that complementary foods for children under the age of 3 years should not be fortified with NaFeEDTA because the amounts required for effective fortification would exceed the acceptable daily intake (ADI) of EDTA $\left(1.9 \mathrm{mg} / \mathrm{kg}\right.$ body weight/ day). ${ }^{30}$ If complementary foods were fortified with NaFeEDTA to supply $75 \%$ of the FAO/WHO RNIs for iron (this assumes the complementary food is consumed to supply $25 \%$ of daily energy requirements or more), then the ADI would be exceeded for infants and young children aged 6-36 months. Therefore, in order to fortify infant foods with NaFeEDTA, the ADI of EDTA would need to be re-evaluated. This would include long-term toxicology testing in rodents with the aim of increasing the ADI. It may be possible to lower the amount of EDTA while maintaining the enhancing effect by mixing NaFeEDTA with ferrous sulphate. A final possibility is ferrous bisglycinate. While this iron compound is absorbed from cereal foods 2-3-fold better than ferrous sulphate, like ferrous sulphate, it has been reported to cause fat oxidation during storage and adverse color reactions. ${ }^{30}$ However, both ferrous sulphate and ferrous bisglycinate could be used if antioxidants were added.

Elemental iron. Iron absorption by infants and children from elemental iron powders has not been investigated due to the difficulty and expense of making isotopically labeled iron powders with identical physical and chemical properties as the commercial powders. Efficacy studies with iron powders have been made mainly in adults. If elemental iron powders are used for food fortification, it is important to specify the form of elemental iron according to its method of manufacture. There are five different elemental iron powders. These are electrolytic, carbonyl, and three forms of reduced iron, i.e., H-reduced, CO-reduced, and atomized reduced. Only electrolytic iron powder is recommended for food fortification ${ }^{8,9}$ and it is suggested that this iron fortificant be added at double the level of ferrous sulphate to allow for its lower absorption. CO-reduced and atomized reduced iron powders are not recommended as their absorption is considered to be too low; H-reduced and carbonyl are considered to require further evaluation. ${ }^{31,32} \mathrm{~A}$ recent efficacy study performed in Thai women consuming iron-fortified wheat snacks indicated that $\mathrm{H}$-reduced iron may be a useful iron fortificant, at least for adults. ${ }^{33}$ However, if ferrous fumarate is less well absorbed in children due to their lower capacity for gastric acid secretion, then other poorly water-soluble iron compounds, such as elemental iron powders, would also be expected to be less well absorbed and proportionally higher amounts would need to be added to the food. In addition, as reported for ferric pyrophosphate, iron absorption from elemental iron powders may be upregulated less well than ferrous sulphate in iron-deficient subjects. 
There is some support for the use of high levels of electrolytic iron for the fortification of cereal-based foods for children. ${ }^{34}$ In a study performed in Chile, children from 4-15 months of age consumed 25-30 g of rice cereal per day, which was either unfortified or fortified with $55 \mathrm{mg}$ electrolytic iron/100 g. The complementary food provided 14-17 mg additional iron per day and was prepared with unfortified formula containing ascorbic acid. Some meat and vegetables were added to the diet from the age of 4 months. At 15 months of age, the prevalence of iron deficiency anemia in the children fed the fortified cereal was only $3 \%$ compared to $15 \%$ in the children fed the non-fortified cereal.

\section{Relative cost of alternative compounds}

Ferrous fumarate is reported to be about $30 \%$ more expensive than ferrous sulphate per unit of iron. ${ }^{35}$ Encapsulation would increase the cost by at least twofold and by up to eightfold depending on the compound chosen. ${ }^{36}$ Electrolytic iron costs about half as much as ferrous sulphate per unit of iron but, because the recommendation is to add twice as much, the final cost would be similar. Ferrous succinate and ferrous gluconate are reported to cost about four times and five times as much as ferrous sulphate, respectively.

\section{CONCLUSION}

Ferrous fumarate is the recommended iron fortification compound for foods for infants and young children when ferrous sulphate causes unacceptable sensory changes. In adults, ferrous fumarate is as well absorbed as ferrous sulphate from iron-fortified complementary foods. Although two reports indicate that iron absorption by infants and young children from ferrous fumaratefortified cereal foods is only about $30 \%$ of that from ferrous sulphate, there is evidence from long-term feeding studies that ferrous fumarate-fortified cereals improve the iron status of infants. The reason for the low RBV of ferrous fumarate in the short-term absorption studies conducted in children is unclear, but it could be related to the iron status of the children, to lower gastric acid secretion in young children compared with adults, or perhaps to the influence of added ascorbic acid. Evidence is accumulating that iron absorption from ferric pyrophosphate, an iron compound poorly soluble in dilute acid, is upregulated less well by iron-deficient women than iron absorption from ferrous sulphate. Such a phenomenon leads to a lower RBV in iron-deficient subjects than in iron-replete subjects.

Current evidence from studies in young children thus indicates that iron absorption from complementary foods fortified with ferrous fumarate is less from the same foods fortified with ferrous sulphate and that, especially in iron-deficient children, foods fortified with ferrous fumarate would be expected to be less efficacious. Since iron deficiency is common in infancy, this lower absorption from ferrous fumarate should be considered when defining the fortification level of complementary foods. The amount of iron added should be based on the amount of daily absorbable iron required from the food, the daily consumption of complementary food, and the expected bioavailability of the added iron.

A final recommendation for the use of ferrous fumarate in complementary foods cannot be given at the present time because it is still necessary to further compare iron absorption and iron efficacy from foods fortified with ferrous sulphate and ferrous fumarate in iron-deficient and iron-replete infants and young children. However, based on current evidence, it can be recommended that ferrous fumarate be added at the same iron concentration as ferrous sulphate in complementary foods designed to maintain iron status in largely ironreplete infants, while it should be added at double or triple the iron level of ferrous sulphate if the target population is largely iron-deficient children, with care taken to ensure that the UL is not surpassed.

\section{Acknowledgments}

This review was prepared as part of SUSTAIN's Food Aid Quality Enhancement Project, one objective of which is to recommend optimal micronutrient formulations for food aid commodities. The following persons provided valuable feedback during the preparation of this paper. Thank you to the SUSTAIN team, especially Elizabeth Turner, Alicia Greenfield, and Sue Wunder; Sean Lynch, Eastern Virginia Medical School; Thomas Bothwell, University of Witwatersrand Medical School; Erick Boy, The Micronutrient Initiative; Kenneth Brown, University of California, Davis; Kathryn Dewey, University of California, Davis; and Dennis Miller, Cornell University. This review was conducted in collaboration with SUSTAIN (http://www.sustaintech.org), through a grant to SUSTAIN from the Bill \& Melinda Gates Foundation.

Declaration of interest. The authors have no relevant interests to declare.

\section{REFERENCES}

1. Domellof M, Cohen RJ, Dewey KG, Hernell O, Rivera LL, Lonnerdal B. Iron supplementation of breast-fed Honduran and Swedish infants from 4 to 9 months of age. J Pediatr. 2001;138:679-687.

2. Lutter CK, Rivera JA. Nutritional status of infants and young children and characteristics of their diets. J Nutr. 2003;133(Suppl):S2941-S2949. 
3. Grantham-McGregor S, Ani C. A review of studies on the effect of iron deficiency on cognitive development in children. J Nutr. 2001;131(Suppl):S649-S666. Discussion S666S668.

4. Lozoff B, Black MM. Impact of micronutrient deficiencies on behaviour and development. In: Pettifor JM, Zlotkin S, eds. Micronutrient Deficiencies during the Weaning Period and the First Years of Life. Vevey \& Basel, Switzerland: Nestic Ltd. \& Kager AG; 2004:119-135.

5. Lozoff B, Jimenez E, Hagen J, Mollen E, Wolf AW. Poorer behavioral and developmental outcome more than 10 years after treatment for iron deficiency in infancy. Pediatrics. 2000;105:E51.

6. Roncagliolo M, Garrido M, Walter T, Peirano P, Lozoff B. Evidence of altered central nervous system development in infants with iron deficiency anemia at 6 mo: delayed maturation of auditory brainstem responses. Am J Clin Nutr. 1998;68:683-690.

7. Hurrell RF. Fortification: overcoming technical and practical barriers. J Nutr. 2002;132(Suppl):S806-S812.

8. Hurrell RF. How to ensure adequate iron absorption from iron-fortified food. Nutr Rev. 2002;60(Suppl):S7-S15.

9. World Health Organization. Guidelines on Food Fortification with Micronutrients. Geneva: World Health Organization and Food and Agriculture Organization; 2006.

10. Pan American Health Organization. Iron compounds for food fortification: Guidelines for Latin America and the Caribbean. Nutr Rev. 2002;60(Suppl):S50-S61.

11. Hurrell RF, Davidsson L, Reddy M, Kastenmayer P, Cook JD. A comparison of iron absorption in adults and infants consuming identical infant formulas. Br J Nutr. 1998;79:3136.

12. Domellof M, Lönnerdal B, Abrams SA, Hernell O. Iron absorption in breast-fed infants: effects of age, iron status, iron supplements, and complementary foods. Am J Clin Nutr. 2002;76:198-204.

13. Hurrell RF, Furniss DE, Burri J, Whittaker P, Lynch SR, Cook JD. Iron fortification of infant cereals: a proposal for the use of ferrous fumarate or ferrous succinate. Am J Clin Nutr. 1989;49:1274-1282.

14. Sarker SA, Davidsson L, Mahmud H, et al. Helicobacter pylori infection, iron absorption, and gastric acid secretion in Bangladeshi children. Am J Clin Nutr. 2004;80:149-153.

15. Perez-Exposito $A B$, Villalpando S, Rivera JA, Griffin IJ, Abrams SA. Ferrous sulfate is more bioavailable among preschoolers than other forms of iron in a milk-based weaning food distributed by PROGRESA, a national program in Mexico. J Nutr. 2005;135:64-69.

16. Hurrell RF, Reddy MB, Dassenko SA, Cook JD. Ferrous fumarate fortification of a chocolate drink powder. $\mathrm{Br} J$ Nutr. 1991;65:271-283.

17. Hurrell RF, Reddy MB, Burri J, Cook JD. An evaluation of EDTA compounds for iron fortification of cereal-based foods. $\mathrm{Br} J$ Nutr. 2000;84:903-910.

18. Fidler MC, Davidsson L, Zeder C, Walczyk T, Hurrell RF. Iron absorption from ferrous fumarate in adult women is influenced by ascorbic acid but not by $\mathrm{Na}(2) E D T A$. Br J Nutr. 2003;90:1081-1085.

19. Davidsson L, Dimitriou T, Boy E, Walczyk T, Hurrell RF. Iron bioavailability from iron-fortified Guatemalan meals based on corn tortillas and black bean paste. Am J Clin Nutr. 2002;75:535-539.

20. Davidsson L, Kastenmayer P, Szajewska H, Hurrell RF, Barclay D. Iron bioavailability in infants from an infant cereal fortified with ferric pyrophosphate or ferrous fumarate. Am J Clin Nutr. 2000;71:1597-1602.

21. Zimmermann MB. The potential of encapsulated iron compounds in food fortification: A review. Int J for Vitam Nutr Res. 2004;74:453-461.

22. Tondeur WC, Schauer CS, Christofides AL, et al. Determination of iron absorption from intrinsically labeled microencapsulated ferrous fumarate (sprinkles) in infants with different iron and hematologic status by using a dual-stable-isotope method. Am J Clin Nutr. 2004;80:1436-1444.

23. Zlotkin SH, Schauer C, Agyei SO, et al. Demonstrating zinc and iron bioavailability from intrinsically labeled microencapsulated ferrous fumarate and zinc gluconate sprinkles in young children. J Nutr. 2006;136:920-925.

24. Faber M, Kvalsvig JD, Lombard CJ, Benade AJ. Effect of a fortified maize-meal porridge on anemia, micronutrient status, and motor development of infants. Am J Clin Nutr. 2005;82:1032-1039.

25. Davidsson L, Sarker SA, Jamil KA, Sultana S, Hurrell R. Regular consumption of a complementary food fortified with ascorbic acid and ferrous fumarate or ferric pyrophosphate is as useful as ferrous sulfate in maintaining hemoglobin concentrations $>105 \mathrm{~g} / \mathrm{L}$ in young Bangladeshi children. Am J Clin Nutr. 2009;89:1815-1820.

26. Moretti D, Zimmermann MB, Wegmuller R, Walczyk T, Zeder C, Hurrell RF. Iron status and food matrix strongly affect the relative bioavailability of ferric pyrophosphate in humans. Am J Clin Nutr. 2006;83:632-638.

27. World Health Organization, Pan American Health Organization. Vitamin and Mineral Requirements in Human Nutrition. Iron, 2nd ed. Geneva: World Health Organization; 2004:246272.

28. Dewey KG, Brown KH. Update on technical issues concerning complementary feeding of young children in developing countries and implications for intervention programs. Food Nutr Bull. 2003;24:5-28.

29. Bothwell TH, MacPhail AP. The potential role of NaFeEDTA as an iron fortificant. Int J Vitam Nutr Res. 2004;74:421-434.

30. Hurrell RF, Lynch S, Bothwell T, et al. Enhancing the absorption of fortification iron - A sustain task force report. Int J Vitam Nutr Res. 2004;74:387-401.

31. Swain JH, Newman SM, Hunt JR. Bioavailability of elemental iron powders to rats is less than bakery-grade ferrous sulfate and predicted by iron solubility and particle surface area. J Nutr. 2003;133:3546-3552.

32. Lynch SR, Bothwell T. A comparison of physical properties, screening procedures and a human efficacy trial for predicting the bioavailability of commercial elemental iron powders used for food fortification. Int J Vitam Nutr Res. 2007;77:107124.

33. Zimmermann MB, Winichagoon P, Gowachirapant S, et al. Comparison of the efficacy of wheat-based snacks fortified with ferrous sulfate, electrolytic iron, or hydrogen-reduced elemental iron: randomized, double-blind, controlled trial in Thai women. Am J Clin Nutr. 2005;82:1276-1282.

34. Walter T, Dallman PR, Pizarro F, et al. Effectiveness of ironfortified infant cereal in prevention of iron deficiency anemia. Pediatrics. 1993;91:976-982.

35. Hurrell R. Iron. In: Hurrell R, ed. The Mineral Fortification of Foods, 1st ed. Surrey, UK: Leatherhead Food RA; 1999:54-93.

36. Moore W, Grant F, Kratky Z, et al. A model for calculating the cost of employing iron absorption enhancement strategies in fortification programs. Int J Vitam Nutr Res. 2004;74:463466. 